\title{
Movement versus focusing of visual attention
}

\author{
MARTIN SHEPHERD \\ University of Liverpool, Liverpool, England \\ and \\ HERMANN J. MÜLLER \\ University of London, London, England
}

\begin{abstract}
In two experiments, we investigated the idea that attention moves through visual space in an analog fashion. The spatial distribution of attention was determined by presenting a spatially informative cue and comparing reaction times to targets at cued and uncued locations as a function of the interval from cue onset to target onset (SOA). Facilitation and inhibition were measured by reference to a neutral condition in which the cue provided no spatial information. In the first experiment, we used a central cue (an arrow), and in the second experiment, we used a peripheral cue (a 50-msec flash). With central cue, the facilitatory effects of the cuing were initially equal for all locations on the indicated side of the display, and then decreased for all locations except the one that had been specifically cued. These results are interpreted as being more consistent with "focusing" of an initially broad "beam" of attention than with "movement" of a narrow beam from fixation to the cued location. With peripheral cues, strong facilitation specific to the cued location was manifest as early as 50 msec after cue onset, but this effect decreased with increasing SOA. Inhibition for uncued locations increased with increasing SOA at a rate that generally reflected their distance from the cued location. Taken together, these results reveal important differences between peripheral and central cues in the generation of attentional selectivity, not just in the time-course of events, but also in the nature of the processes involved.
\end{abstract}

The allocation of attention to a location other than fixation is well documented. Casual observations of this phenomenon go back at least one hundred years, but experimental demonstrations are comparatively recent. Posner and his colleagues have developed a method for determining the locus of attention that is based on the provision of cues (which may or may not be misleading) about the likely location of a target stimulus in advance of the actual stimulus presentation, and measuring the speed with which the target is detected. These experiments (Posner, 1980; Posner, Snyder, \& Davidson, 1980) have shown that spatial cues have dramatic effects on the detectability of stimuli in peripheral vision, even when eye movements are excluded. Reaction times to targets are fast if they appear at cued locations (valid cues) and slow if they appear at uncued locations (invalid cues). Neutral cues, which provide no spatial information and act simply as a temporal warning signal, provide a baseline that enables

The order of authors was decided by the toss of a coin: both authors contributed equally to this work, which was supported by Medical Research Council Grant G84/03193N and Postdoctoral Fellowship Mu773/1-1 from the Deutsche Forschungsgemeinschaft held by the second author. The authors would like to thank C. W. Eriksen and three anonymous reviewers for their valuable comments on earlier versions of this paper. Correspondence should be addressed either to M. Shepherd, Department of Psychology, Chester College, Cheyney Road, Chester CH1 4BJ, U.K., or to H. J. Müller, Department of Psychology, Birkbeck College, University of London, Malet Street, London, WC1E 7HX, U.K. the facilitatory effects of valid cues (benefits) and the inhibitory effects of invalid cues (costs) to be estimated. Varying the interval from cue onset to target onset (SOA) enables the time-course of facilitatory and inhibitory effects to be mapped out. The results of these studies are consistent with the idea that attention can be shifted from fixation to a different part of the visual field without making a corresponding eye movement.

Recently, there has been considerable interest in the nature of this attention shift: How rapidly can it be accomplished? How extensive is the attended area? And, in particular, is the attention "movement" itself analog or digital in nature; using the "spotlight" metaphor, is the light swept across the visual field, or is it switched off, moved, and then switched back on again?

Shulman, Remington, and McLean (1979) reasoned that if the attention movement is analog, locations between the origin and the destination of the movement should show the effects of attention at some time during the movement. They used a display with two possible target locations on both sides of fixation: near $\left(8^{\circ}\right)$ and far $\left(18^{\circ}\right)$. Central arrow cues indicated that the far location was the most likely position for the target, and SOA varied from 50 to 500 msec. The far-near RT difference was about $10 \mathrm{msec}$ at the shortest SOA, about $20 \mathrm{msec}$ at 150 - to 200-msec SOAs, and about 10 msec at longer SOAs. Shulman et al. attributed the greater far-near difference at intermediate SOAs to the passage of attention through the near location, supporting the analog-movement model. 
However, this interpretation is only feasible if any effects of eccentricity are constant across all SOAs and cuing conditions. Comparison of near and far locations is a rather indirect way to look at these effects anyway. What is needed is an absolute measure of the amount of facilitation at these two locations, and for this a neutral cuing condition, in which the cue provides no spatial information, is required. ${ }^{1}$

Remington and Pierce (1984) used neutral cues, but found no difference in the time-course of facilitation between near and far locations. They concluded that attention movements (like eye and hand movements) have a velocity proportional to distance, resulting in more or less constant movement times over a range of distances. However, there was an important difference in the method of their experiment and of that of Shulman et al. (1979). In the Remington and Pierce study, near and far conditions were blocked, so that there were only two possible target locations (one on either side of fixation). The finding of no difference between near and far conditions might be explained by supposing that the number of possible target locations is more important than the actual eccentricity of the cued location. The blocking of near and far locations also precluded a crucial test of the analog-movement model: What happens to locations beyond the (near) cued location? According to the analog-movement model, these locations either should never show facilitation (with no overshoot of the attention movement), or should not show facilitation until after maximum facilitation at the cued location has been reached (with overshoot).

As an alternative to a movement model, consider a focusing model, such as the "zoom-lens" model proposed by Eriksen and Yeh (1985; see also Murphy \& Eriksen, 1987). In this model, attention is initially a wide-focus "beam," covering a large area of the visual field, and being of correspondingly low power. When the cue starts to take effect, the beam becomes increasingly narrowly focused, until it is highly concentrated on the cued location. Such a model might be able to account for the results of Shulman et al. (1979) by proposing that soon after cue onset, the whole of the cued hemifield (at least up to $18^{\circ}$ eccentricity) receives weak facilitation. Later, attention is concentrated on the cued location, and no other location shows facilitation. Thus, when the cued location is also the most eccentric location, an illusion of analog attention movement is created. In contrast to the analogmovement model, the focusing model predicts that when the near location is cued, the far location will show early facilitation, as long as it falls within the broad focus of attention. Note that this model can only explain the farnear differences in Shulman et al.'s experiment if any effects of eccentricity vary with SOA. One of the aims of the present study is to establish whether this is the case.

The idea that attention can be distributed (albeit weakly) over large areas of the visual field requires some comment. Most researchers have concluded that the attended area is typically about $1^{\circ}$ or less in diameter (e.g., Eriksen \& Hoffman, 1972, 1973; Humphreys, 1981). However, there are three important points of qualification. First, in Eriksen and Hoffman's experiments, the facilitatory effects of precues (i.e., reduction in response competition of incompatible "noise" letters) did not reach a maximum until about $250 \mathrm{msec}$ after cue onset, so the possibility of a broader focus at shorter SOAs was not ruled out (see also Murphy \& Eriksen, 1987). Second, several studies (e.g., LaBerge, 1983; Müller \& Findlay, 1987) have shown that the extent of the attended area can be considerably modified by task demands (varying a priori signal probabilities for possible target locations, for example), which suggests considerable flexibility in the allocation of resources. Third, the visual acuity requirements of a task may be crucial in determining the distribution of attention. In tasks that make great demands on acuity (e.g., letter identification), attention is likely to be concentrated on or near the fovea, but tasks that make fewer demands on acuity (e.g., detection of luminance increments) may allow attention to be more widely distributed. It is therefore possible that very large areas can be attended in tasks in which minimal demands on acuity are made.

Another factor that could influence the pattern of attentional effects in spatial-cuing tasks is whether cues are central or peripheral. This is of interest for several reasons. First, it is widely believed that central cues give rise to a slow-onset, controlled-orienting process, whereas peripheral cues give rise to a rapid-onset, automaticorienting process (Jonides, 1981; Müller \& Rabbitt, in press). The question then arises as to whether shifts of attention follow the same pattern for both of these processes. Second, peripheral cues tend to attract saccadic eye movements as well as attention (e.g., Posner, Crippin, Cohen, \& Rafal, 1986), and saccade latencies are shorter for "reflexive" saccades than for "voluntary" saccades. Questions of interest here concern the possible involvement of the eye-movement system in the allocation of attention (and vice versa), even when actual eye movements are suppressed (Klein, 1980; Rizzolati, Riggio, Dascola, \& Umilta, 1987; Shepherd, Findlay, \& Hockey, 1986). If shifts of attention are closely linked to saccade programming, then there may be parallels to be drawn between controlled-orienting and voluntary saccades, and automatic-orienting and reflexive saccades. In the present experiments, we therefore included a comparison of central and peripheral cuing conditions to enable these questions to be explored.

In Experiment 1, we compared cuing of the far location with cuing of the near location, using the same display throughout. This experiment was designed to replicate that of Shulman et al. (1979) (with an added neutral cuing condition) and to test the contrasting predictions of the analog-movement and focusing models. When the far location is cued (as in the experiment of Shulman et al.), the movement model predicts that at short SOAs there should be greater facilitation for the near location than for the far location, whereas at longer SOAs there should be more facilitation for the far location. In contrast, the 
focusing model predicts that there should be equal facilitation for both far and near locations at short SOAs (when attention is broadly distributed), and greater facilitation for the far location at longer SOAs (when attention is narrowly focused). When the near location is cued, the movement model predicts that neither location should show facilitation at very short SOAs, and that there should be facilitation for the near location at longer SOAs. According to this model, facilitation for the far location should never be observed, except perhaps at the longest SOAs when some overshoot of attention movement might occur. In contrast, the focusing model predicts that both near and far locations should show equal facilitation at short SOAs; and as SOA increases, the near location should show increasing facilitation and the far location should show decreasing facilitation.

\section{EXPERIMENT 1}

\section{Method}

Apparatus. The stimuli were presented on a Hewlett-Packard 1321 A X-Y monitor with P31 phosphor, driven by an LSI 11/23 computer using a CED 502 interface. The display was controlled by the EMDISP system (Shepherd, 1984). Viewing distance (defined by a chin rest) was $40 \mathrm{~cm}$. The display consisted of five boxes, each $2^{\circ}$ across, one in the center of the screen and the others $10^{\circ}$ and $20^{\circ}$ to the left and right of center. The center box had a small dot in the middle to aid fixation. The neutral and spatial cues were about $0.5^{\circ}$ across and were always presented in the center box. The target was a bright, filled square about $0.3^{\circ}$ across. The laboratory was dimly illuminated by an incandescent lamp placed behind the screen (to eliminate reflections). Stimulus luminance was $0.1 \mathrm{ftL}$, and screen background luminance was $0.01 \mathrm{ftL}$.

Design. The display was made up of five boxes arranged horizontally. Cues appeared in the center box, and targets could appear in any of the other four boxes. There were equal numbers of neutral and spatial cues, randomly intermixed. The neutral cue was a cross, which indicated that the target was equally likely to appear in any of the four possible locations. The spatial cue was an arrow pointing left or right, which indicated that the target was seven times more likely to appear at the cued location (far or near, depending on instructions) than in any of the other three locations (targets never appeared in the center box). Four SOAs $(50,150$, 200 , and $500 \mathrm{msec}$ ) occurred equally often and were randomized with respect to the other conditions. In order to discourage anticipations, $20 \%$ of the trials were "catch" trials (on which no target appeared), randomly but fairly evenly distributed throughout each block of trials.

Subjects. Thirteen subjects with normal or corrected-to-normal vision were paid $f 2$ per hour for their participation.

Procedure. Each trial consisted of a cue, followed (at one of the four SOAs) by a target (except on catch trials). The subjects' task was to press a single key as quickly as possible whenever a target appeared. The response to the target was followed by a 1.5 -sec response-stimulus interval. The subjects were instructed to keep their eyes fixed on the center box throughout each block of trials. In pilot studies, eye movements were monitored using an infrared corneal reflection method (Findlay, 1974), and it was found that subjects fixated very reliably. In direct observation during the experiments themselves (i.e., observation by the experimenters), saccades were detected on less than $1 \%$ of the trials; these few trials were not excluded from further analysis. ${ }^{2}$ The subjects were informed about the meanings of the two types of cue, and were given a block of practice trials before starting the experimental blocks (subjects unfamiliar with spatial-cuing experiments also participated in a preexperimental practice session). There were 184 trials per block, five blocks per session, and four sessions (arranged on consecutive days whenever possible). The identity of the cued location (near or far) was constant for a block of trials, and blocks were presented in random order. Trials on which a subject recorded an RT of less than $150 \mathrm{msec}$ or greater than $1 \mathrm{sec}$ were rerun at the end of each block.

\section{Results and Discussion}

The data were collapsed across left and right, and median RTs for each subject under each condition were computed. The means of these scores are shown in Table 1. Figure 1 shows the corresponding mean benefits and costs for each SOA for near and far locations on the same and opposite sides of the cue.

An analysis of variance (ANOVA) was performed with main terms for cued location (far/near), target location (far/near), cue type (same/neutral/opposite), and SOA. This analysis yielded significant main effects of cued location $[F(1,12)=8.31, p<.02]$, target location $[F(1,12)=75.87, p<.0001]$, cue type $[F(2,12)=56.73$, $p<.0001]$, and SOA $[F(3,36)=24.47, p<.0001]$. Several two- and three-way interactions were significant, but these can be interpreted only in terms of the four-way interaction of cued location $\times$ target location $\times$ cue type $\times$ SOA $[F(6,72)=3.19, p<.01]$.

First, let us consider the conditions in which the cued location was the far location. If we consider only far-near differences on the cued side, our results replicated those of Shulman et al. (1979): far-near differences were 9, 12, 12 , and $9 \mathrm{msec}$ for SOAs of $50,150,200$, and $500 \mathrm{msec}$, respectively. However, comparison of each of the conditions with its corresponding neutral cuing condition revealed a more complicated picture (see Table 1 and Figure 1). Both same-far and same-near locations showed

Table 1

Mean Reaction Times (in msec) to Targets in Near and Far Locations as a Function of Cuing and SOA (in msec)

\begin{tabular}{clcccc}
\hline \multirow{2}{*}{$\begin{array}{c}\text { Target } \\
\text { Location }\end{array}$} & \multicolumn{1}{c}{$\begin{array}{c}\text { Cue } \\
\text { Type }\end{array}$} & \multicolumn{5}{c}{ S0 } & 150 & 200 & 500 \\
\hline \multirow{5}{*}{ Far } & \multicolumn{5}{c}{ Cued Location-Far } \\
& Same & $316 \ddagger$ & $276 \ddagger$ & $277 \ddagger$ & $255 \ddagger$ \\
& Neutral & 327 & 297 & 291 & 275 \\
& Opposite & 333 & $309 *$ & $322 \ddagger$ & $309 \ddagger$ \\
Near & Same & $309 \ddagger$ & $264 \ddagger$ & $265 \dagger$ & $246 \ddagger$ \\
& Neutral & 323 & 279 & 275 & 257 \\
& Opposite & 329 & $291 \ddagger$ & $298 \ddagger$ & $283 \ddagger$ \\
Neutral & Far-Near & $+4 \ddagger$ & $+18 \ddagger$ & $+16 \ddagger$ & $+18 \ddagger$ \\
& & Cued Location- & Near & & \\
Far & Same & $292 \ddagger$ & $248 \ddagger$ & 262 & 263 \\
& Neutral & 307 & 271 & 269 & 254 \\
& Opposite & 311 & $302 \ddagger$ & $318 \ddagger$ & $307 \ddagger$ \\
Near & Same & $285 \ddagger$ & $233 \ddagger$ & $242 \ddagger$ & $226 \ddagger$ \\
& Neutral & 299 & 253 & 257 & 239 \\
& Opposite & 298 & $272 \ddagger$ & $281 \ddagger$ & $291 \ddagger$ \\
Neutral & Far-Near & $+8 *$ & $+18 \ddagger$ & $+12 \ddagger$ & $+15 \ddagger$ \\
\hline
\end{tabular}

Note-RT benefits and costs using simple main effects: ${ }^{*} p<.05$, $\dagger p<.01, \ddagger p<.005$. 
SAME SAME CEN- OPP. OPP.
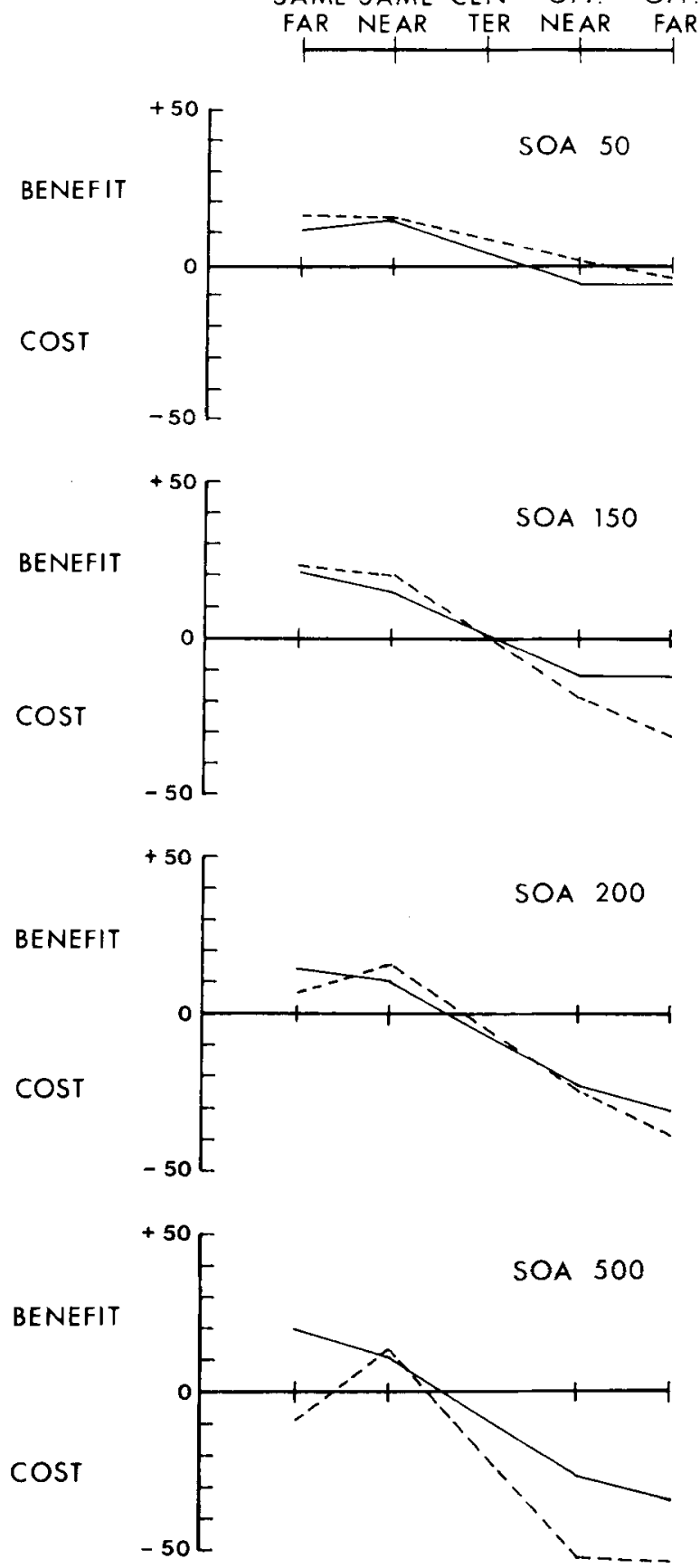

FAR CUED

NEAR CUED

Figure 1. Mean reaction-time benefits and costs (in msec) for near and far locations on the same and opposite sides of the cue for each SOA (in msec) in Experiment 1.

significant facilitation at all four SOAs, reaching a maximum at the 150-msec SOA (same-far: facilitation at the $50-\mathrm{msec}$ SOA was less than at the 150 - and $500-\mathrm{msec}$ SOAs: $p<0.025$ and $p<0.05$, respectively; Tukey test), with a (nonsignificant) tendency for facilitation to decrease for the uncued location (near), although it was maintained for the cued location (far), at longer SOAs. The locations on the opposite side showed increasing inhibition with increasing SOA, with a tendency for the inhibition to be greater for opposite-far (the location farthest from the cued location) than for opposite-near location, which suggests an attentional gradient.

The comparison of far and near locations for trials with neutral cues (neutral far-near in Table 1) shows that the eccentricity effect did vary with SOA, and demonstrates the importance of using a neutral cuing condition rather than simply comparing same-far and same-near locations. If the same interaction of eccentricity and SOA was present in the experiment of Shulman et al. (1979), then a focusing model could deal with their data. In our data, the divergence between same-far and same-near locations at intermediate SOAs is largely attributable to the fact that the eccentricity effect was not constant across SOAs. The most obvious reason responses to targets in near locations should be faster than responses to targets in far locations is the gradient of sensitivity from the fovea to more peripheral parts of the retina. However, the gradient in retinal sensitivity fails to explain why the eccentricity effect should vary with SOA. One possible explanation is that at short SOAs, a large proportion of the available resources are taken up by processing the cue (McLean \& Shulman, 1978), so that all locations are relatively disadvantaged.

Now let us turn to the conditions in which the near location was cued to be most likely. As predicted by the focusing model, the facilitatory effect of the spatial cue was more or less equal for both cued (same-near) and uncued (same-far) locations up to the 150-msec SOA, which indicates that both locations initially received attention. From the 200- to the 500-msec SOA, facilitation decreased somewhat for the cued (near) location, and decreased very markedly for the uncued (far) location. Again, inhibitory effects for uncued locations on the opposite side (oppositefar and opposite-near) increased with increasing SOA, at a rate that tended to be faster the greater the distance from the cued location, which suggests an attentional gradient.

In the present data, both cued and uncued locations on the indicated (same) side showed significant facilitation at almost all SOAs. This led us to ask whether the degree of facilitation for the cued location diverged significantly from the degree of facilitation for the uncued location on the same side of the display. To answer this question, the differences between each condition and its corresponding neutral condition (i.e., benefits and costs) were computed for each subject and were examined in an ANOVA with main terms for cued location (far/near), cue type (same/opposite), target location (far/near), and SOA. This ANOVA yielded significant main effects of cue type $[F(1,12)=71.32, p<.001]$ and $\operatorname{SOA}[F(3,36)=11.03$, $p<.0001]$, and marginally significant main effects of cued location $[F(1,12)=3.32, p<.095]$ and target location $[F(1,12)=4.15, p<.065]$. Several two- and three-way interactions were significant, but they can only be interpreted in terms of the significant four-way inter- 
Table 2

Comparisons of Reaction-Time Benefits and Costs for Cued and Uncued Locations on the Same Side of the Display

\begin{tabular}{llcrr}
\hline \multirow{2}{*}{$\begin{array}{c}\text { Target } \\
\text { Location }\end{array}$} & \multicolumn{4}{c}{ SOA } \\
\cline { 2 - 5 } & 50 & \multicolumn{4}{c}{150} & 200 & 500 \\
\hline \multicolumn{5}{c}{ Cued Location-Far } \\
Near & +11 & +21 & +14 & +20 \\
$F$ ratio & +14 & +15 & +10 & +11 \\
$p$ & 0.42 & 2.13 & 0.79 & 4.68 \\
& n.s. & n.s. & n.s. & $<.01$ \\
Far & \multicolumn{2}{c}{ Cued Location-Near } & \\
Near & +15 & +23 & +7 & -9 \\
$\quad F$ ratio & +14 & +20 & +15 & +13 \\
$p$ & 0.04 & 0.14 & 1.30 & 9.12 \\
\hline & n.s. & n.s. & n.s. & $<.005$ \\
\hline
\end{tabular}

Note- $d f=3,36$. SOA expressed in msec.

action of cued location $\times$ cue type $\times$ target location $\times$ SOA $[F(3,36)=4.11, p<.015]$. Planned comparisons (using the simple main effects procedure described by Kirk, 1968, p. 179) were used to assess the differences between facilitation for the cued location and the uncued location on the same side. These comparisons are summarized in Table 2.

The only significant divergences in the amount of facilitation at cued and uncued locations on the same side of the display occurred at the 500-msec SOA. These findings disconfirm several predictions of the analog-movement model. When the cued location is the far location, the movement model predicts no facilitation for the far (cued) location at very short SOAs, and greater facilitation for the near (uncued) location at intermediate SOAs. When the cued location is the near location, the movement model predicts no facilitation for the far location, except possibly at long SOAs. All of these predictions are disconfirmed by our data. In contrast, the observed effects in the present experiment were more consistent with the focusing model, which predicts that soon after cue onset both locations on the cued side will be attended, followed by a narrowing of the focus on the cued location. One aspect of our data that remains puzzling from this perspective is that narrowing of the focus did not seem to result in greater concentration of resources, as the largest facilitation occurred at the 150 -msec SOA. We shall return to this issue in the general discussion.

\section{EXPERIMENT 2}

The second experiment was designed to explore the effects of peripheral cuing in the same experimental design. Peripheral cues have been shown to have powerful facilitatory effects on the processing of subsequent targets (Jonides, 1981; Müller \& Rabbitt, in press). The finding that facilitatory effects occur even when subjects are instructed to ignore spatially noninformative peripheral cues (Jonides), or when flashed locations are less likely to contain targets (Müller \& Rabbitt), suggests that peripheral cues elicit an automatic orienting response. The purpose of the following experiment was to look for evidence of attention movement (or focusing) when attention is drawn by peripheral cues. The provision of informative cues enables direct comparisons with Experiment 1.

It should be noted that there are some difficulties in creating a neutral cuing condition using peripheral cues. In the first experiment, a neutral (noninformative) cue was simply a symbol (a cross) which was readily distinguishable from the informative cue (an arrow) and which appeared in the same location (at fixation). However, with direct peripheral cues (a 50-msec brightening of the indicated box), it is not possible to produce a neutral condition in an analogous way; any peripheral cue will act as a pointer to location as well as a temporal warning signal. The only possible solution seemed to be to brighten all possible target locations. This gives a temporal warning signal without giving information as to the likely location of the target. However, since the neutral cue produced a greater energy change in the display than did a spatial cue (four flashes versus one), RTs on neutral trials might have been affected by factors (e.g., alerting effects) that may have had no (or less) influence on valid- and invalid-cue trials. This condition proved to be reasonably neutral, however, insofar as (1) the pattern of RTs across SOAs was very similar to that in the central cuing experiment, and (2) the RTs for the neutral condition fell between the RTs for cued and uncued locations.

\section{Method}

The method was the same as in Experiment 1, except that the cue consisted of a 50 -msec increase in luminance (doubling of refresh rate) of a single box (spatial cue) or all four target boxes (neutral cue).

Subjects. Nine subjects with normal or corrected-to-normal vision were paid $£ 2$ per hour for their participation.

\section{Results and Discussion}

Table 3 shows the RTs for each condition, and Figure 2 shows the corresponding benefits and costs for locations on the same and opposite sides of the cue, for each SOA.

Table 3

Mean Reaction Times (in msec) to Targets in Near and Far Locations as a Function of Cuing and SOA (in msec)

\begin{tabular}{llllll}
\multicolumn{2}{c}{ Target } & Cue & \multicolumn{5}{c}{ SOA } \\
\cline { 3 - 6 } Location & Type & 50 & 150 & 200 & 500 \\
\hline \multirow{5}{*}{ Far } & Cued Location-Far & \\
& Same & $295 \ddagger$ & $265 \ddagger$ & $264 \ddagger$ & 277 \\
& Neutral & 333 & 284 & 282 & 276 \\
& Opposite & 328 & 290 & 292 & $306 \ddagger$ \\
Near & Same & 310 & $249 *$ & 249 & $301 \ddagger$ \\
& Neutral & 306 & 266 & 256 & 260 \\
& Opposite & 301 & 262 & 264 & $286 \ddagger$ \\
Neutral & Far-Near & $+27 \ddagger$ & $+18 \ddagger$ & $+26 \ddagger$ & $+16 \ddagger$ \\
& & Cued Location-Near & & \\
Far & Same & 333 & $286 *$ & $292 \ddagger$ & $306 \ddagger$ \\
& Neutral & 319 & 266 & 267 & 263 \\
& Opposite & 323 & $286 \ddagger$ & $287 \ddagger$ & $300 \ddagger$ \\
Near & Same & $274 \ddagger$ & 244 & 241 & 239 \\
& Neutral & 290 & 250 & 243 & 245 \\
& Opposite & 300 & 257 & $262 \ddagger$ & $269 \ddagger$ \\
Neutral & Far-Near & $+29 \ddagger$ & $+16 \ddagger$ & $+24 \ddagger$ & $+18 \ddagger$ \\
\hline Note & &
\end{tabular}

Note-RT benefits and costs using simple main effects: ${ }^{*} p<.05$, $\dagger p<.01, \ddagger p<.005$. 

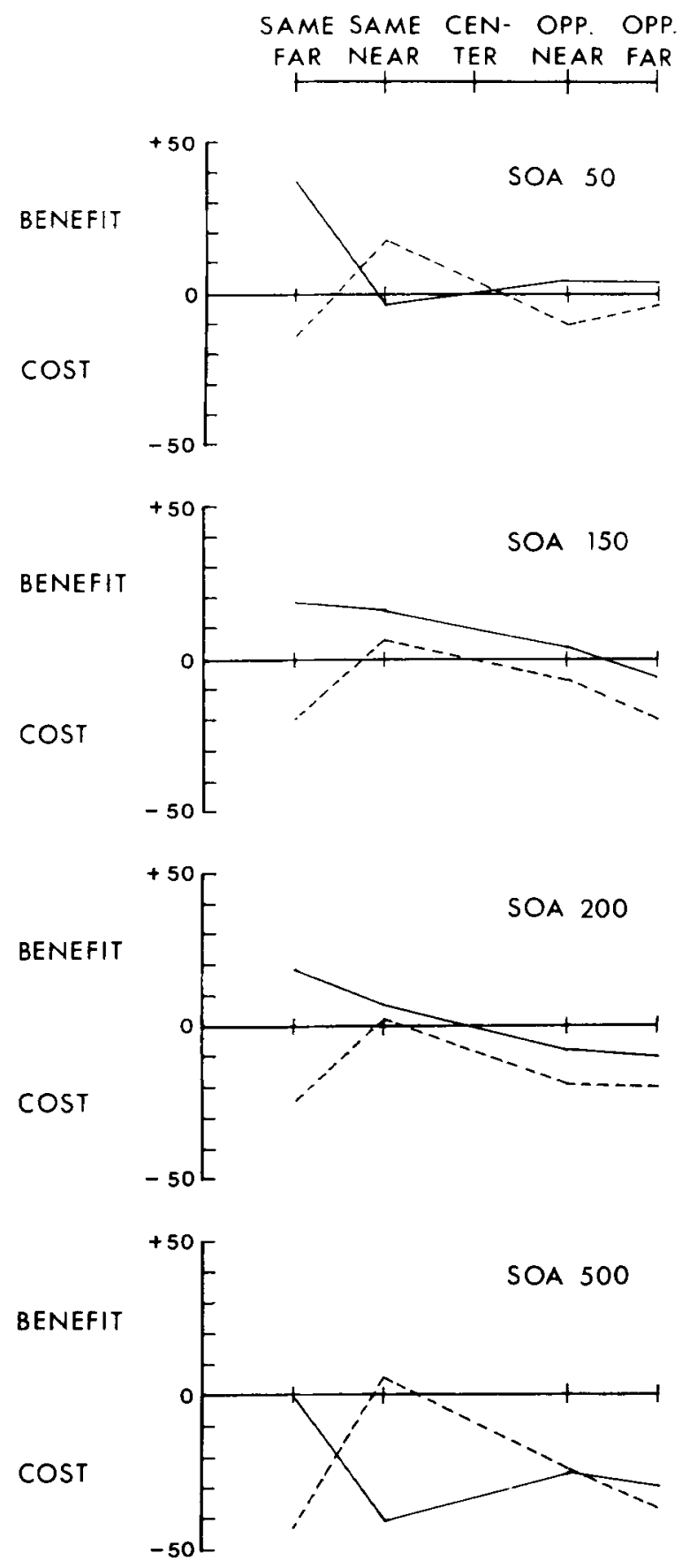

FAR CUED

NEAR CUED

Figure 2. Mean reaction-time benefits and costs (in msec) for near and far locations on the same and opposite sides of the cue for each SOA (in msec) in Experiment 2.

An ANOVA was performed with the factors cued location (far/near), target location (far/near), cue type (same/neutral/opposite), and SOA. This analysis yielded significant main effects of target location $[F(1,8)=$ $184.76, p<.0001]$, cue type $[F(2,8)=5.19, p<.02]$, and SOA $[F(3,24)=13.36, p<.0001]$. Several twoand three-way interactions were significant, but these can only be interpreted in terms of the four-way interaction of cued location $\times$ target location $\times$ cue type $\times$ SOA $[F(6,48)=2.27, p<.025]$.

As in Experiment 1, deviations from neutral conditions were calculated separately for each subject, and the resulting difference (i.e., benefit and cost) scores were subjected to an ANOVA with main terms for cued location (far/near), cue type (same/opposite), target location (far/near), and SOA. This analysis yielded significant main effects of cued location $[F(1,8)=33.33, p<.0005]$, cue type $[F(1,8)=9.44, p<.02]$, target location $[F(1,8)$ $=5.88, p<.05]$, and SOA $[F(3,24)=6.29, p<.003]$. There were significant interactions of cued location $\times$ target location $[F(1,8)=17.75, p<.003]$, cued location $\times \operatorname{SOA}[F(3,24)=5.68, p<.005]$, and cued location $\times$ cue type $\times$ target location $[F(1,8)=12.51, p<.01]$. The four-way interaction of cued location $x$ cue type $x$ target location $\times$ SOA was marginally significant $[F(3,24)$ $=2.50, p<.085]$.

The only locations that showed significant facilitation were those that had been specified by the cue. ${ }^{3}$ Facilitation was most marked 50 msec after cue onset, and decreased rapidly with increasing SOA. All uncued locations showed increasing inhibition with a time-course that generally reflected their distance from the cued location.

These results show that peripheral cues at short SOAs were more effective than were central cues at all SOAs (see also Jonides, 1981; Müller \& Rabbitt, in press). One possible explanation is that the focusing process is simply much faster with peripheral cues. Alternatively, it could be that peripheral cues give rise to a narrow attentional focus so that only a small area of the visual field is ever facilitated. In either case, there was no evidence of an increasingly narrow focus with longer SOAs, as there was with central cues.

The interaction between eccentricity and SOA for neutral cues, which was observed in Experiment 1, was not obtained in Experiment 2 (see neutral far-near in Table 3). This constitutes interesting evidence that eccentricity effects vary with type of cue. One possibility is that with direct peripheral cues, processing of the cue (at the shortest SOAs) is not as resource-demanding as with symbolic central cues.

\section{GENERAL DISCUSSION}

Several assumptions can be identified as important to some current views of visual attention: (1) Attention is best modeled in terms of a spotlight; (2) the beam of the spotlight is narrow, probably $1^{\circ}$ or less in diameter; (3) shifts of attention from one location in the visual field to another correspond to movements of the beam; (4) these movements are analog in nature (i.e., passing through all intermediate locations); and (5) the movements have a constant velocity (Shulman et al., 1979; Tsal, 1983 ) or a velocity proportional to distance (Remington \& Pierce, 1984). 
The results of the present experiments call into question all of these assumptions. First, Experiment 1, using central cues, demonstrated that two locations $10^{\circ}$ apart are equally facilitated at short SOAs, which indicates that the width of the beam can be very broad. Presumably, central (i.e., internally controlled) allocation of attention is flexible and sensitive to the demands being made on the system. In particular, tasks that make few demands on acuity (such as detection of suprathreshold luminance increments) allow flexible distribution of resources.

Our experiments offer no evidence that attention can be "moved" from one location to another, merely that attentional resources can be redistributed in response to spatially informative cues. We claim that the same is true of all experiments that have claimed to demonstrate "movement" of attention. The present data suggest that the movement metaphor is potentially misleading when applied to the phenomenon of spatial attention. The finding (Experiment 1) that locations beyond the (near) cued location received as much facilitation as did the cued location at short SOAs (and less facilitation at longer ones) is particularly damaging for the analog-movement model.

If the movement metaphor is inappropriate, then debates about whether attention moves with a fixed velocity or with a velocity proportional to distance are potentially vacuous, and the issues would be clarified by restating them without reference to movement. Remington and Pierce (1984) found no effect of distance on the time-course of attentional effects, as long as there were only two possible target locations. In the "light" of our findings, it appears that aspects of the display, such as the number of possible target locations and whether they are clearly marked, are potentially more important determinants of time-course patterns than is target eccentricity per se. Moreover, if movement is an inappropriate metaphor, the question of whether attention shifts are analog or digital in nature loses much of its point.

Our data fit a focusing model quite well. In the central cuing experiment, an initially broad focus is suggested by the equal facilitation for near and far locations at short SOAs, and narrowing of the focus is suggested by the subsequent decrease in facilitation for the uncued location. The data from the peripheral cuing experiment are consistent with the idea that peripheral cues produce a narrow focus very soon after their onset, as the cued location was the only one that showed any facilitation.

Eriksen and Yeh's (1985) "zoom-lens" model predicts that attentional effects will be stronger with narrow than with broad focuses. If this is so, then the finding that peripheral cues produced greater maximum facilitation (about $27 \mathrm{msec}$ at the 50 -msec SOA) than central cues (16 msec averaged across all SOAs) suggests that peripheral cues give rise to initially narrower focuses. However, it is not clear from this account why facilitation in the central cuing experiment never reached the higher level of the peripheral cuing experiment (see also Müller \& Rabbitt, in press). In fact, with central cues, there was no increase in facilitation of the cued location from the 200 - to the 500 -msec SOA, so there is correspondingly little evidence of increasing strength with narrowing of focus. The focusing account also fails to explain why, with peripheral cues, facilitation decreased from its initial maximum at the $50-\mathrm{msec}$ SOA. ${ }^{4}$

Possibly the most satisfying account of the present data is to be found in a "premotor" theory of attention, in which the allocation of attention to a location distant from fixation is closely identified with the preparation to make a saccadic eye movement to that location. As far as central cuing is concerned, Klein (1980) rejected such a theory because he failed to detect any effect of expecting to make an eye movement on making a keypress, or vice versa.

However, Shepherd et al. (1986) found that when both attention and saccades were directed by a central arrow, attention and eye movements showed clearly interactive effects. In that study, making an eye movement to a location facilitated manual responses to targets at that location, and attending to a location that was likely to contain a target facilitated eye movements to that location. The most important result from the Shepherd et al. study was that when the targets for attention movement and eye movement were on opposite sides of fixation, the effects of preparing to make an eye movement were stronger than the effects of spatial cuing on the distribution of attention, and these effects were present at SOAs as short as $50 \mathrm{msec}$ (typically some $200 \mathrm{msec}$ before the start of the saccade). It is therefore possible that even when eye movements are not allowed, the early stages of saccade programming are still executed and affect the distribution of attention. ${ }^{5}$

This hypothesis has recently been put forward by Rizzolati et al. (1987), who examined the costs associated with targets appearing at unexpected locations. They found that costs increased as a function of distance from the cued location, but there was an additional "meridianal" effect: crossing either the vertical or the horizontal meridian cost an extra $20 \mathrm{msec}$. The distance effect is consistent with the idea of an attentional gradient, but an unaugmented gradient theory cannot explain the meridianal effect. The vertical meridian effect might be explained in terms of transfer of activation from one hemisphere to the other across the corpus callosum (Hughes \& Zimba, 1985), but this account fails for the horizontal meridian. In contrast, a premotor theory could predict both the meridianal effect and the distance effect.

According to this explanation, making a manual response to a target involves programming a saccade to the location of the target. If the target appears in an unexpected location, the saccade program must be modified, and the degree of modification is reflected in the final manual RT. Following the "hierarchical" model of motor programming proposed by Rosenbaum, Inhoff, and Gordon (1984), Rizzolati et al. (1987) suggest that reprogramming the direction of the saccade involves greater modification than does reprogramming the amplitude. The meridianal effect would correspond to reprogramming the 
direction, and the distance effect would correspond to reprogramming the amplitude of the saccade.

Several features of the present data fit this analysis. The facilitation for the whole hemifield, following a central cue, would be attributed to the preparation of an eye movement in the appropriate direction. Assuming that saccade direction is initially programmed independently of amplitude, cued and uncued locations should show initially equal facilitation if they are in the same hemifield. The later decrease in facilitation for the uncued location would be attributed to the effects of starting to program the saccade amplitude. The inhibition of uncued locations in the uncued hemifield would initially result from reprogramming the direction of the movement, and all these locations would show equal inhibition. Once programming of amplitude was under way, these locations should show more inhibition the greater their distance from the cued location. With peripheral cues, it could be assumed that the occurrence of a stimulus event (i.e., a cue) at the destination location of the eye movement would trigger "automatic" programming, which occurs much faster (it is well established that "reflexive" saccades have much shorter latencies than do "voluntary" saccades) and has precisely defined amplitude parameters. As a result, the cued location would show early and strong facilitation, whereas all uncued locations would show inhibition as a function of their distance from the cued location. The later decrease in facilitation for the cued location would occur because, at longer SOAs, oculomotor preparation for the cued location must be maintained by the same "controlled" process that is elicited by central cues (see also Müller \& Rabbitt, in press).

\section{CONCLUSION}

The present data clearly show that, with central cues, the cued location and the uncued location on the same side of fixation show equal facilitation at short SOAs, and a decrease in the cuing effect for the uncued location is shown at longer SOAs. This effect is obtained even when the uncued location is further from fixation than is the cued location. These results provide strong evidence against the idea that attention should be conceived of as a narrow-beam spotlight that can be swept across the visual field. If we must use a spotlight metaphor, a more appropriate description is that of a beam that is initially very broad and takes time to focus on a small area around the cued location. In the present study, with peripheral cues, absolute facilitation was stronger and reached a maximum earlier than with central cues, and none of the uncued locations showed significant facilitation. This result is also interpretable in terms of a focusing model, in which peripheral cues rapidly produce a narrow focus. However, the present data offer no direct evidence of focusing with peripheral cues, as facilitation actually decreased after the maximum at very short SOAs. As an alternative to a focusing model, the premotor theory of attention advanced by Rizzolati et al. (1987) offers a useful perspective on the present data. It remains to be seen whether such a theory can be made to account for all the available data.

\section{REFERENCES}

Eriksen, C. W., Hoffman, J. E. (1972). Some characteristics of selective attention in visual perception determined by vocal reaction time. Perception \& Psychophysics, 11, 169-171.

Eriksen, C. W., \& Hoffman, J. E. (1973). The extent of processing of noise elements during selective encoding from visual displays. Perception \& Psychophysics, 14, 155-160.

Eriksen, C. W., MURPhy, T. D. (1987). Movement of attentional focus across the visual field: A critical look at the evidence. Perception \& Psychophysics, 42, 299-305.

ERIKSEN, C. W., \& YEH, Y.-Y. (1985). Allocation of attention in the visual field. Joumal of Experimental Psychology: Human Perception \& Performance, 11, 583-597.

FindLAY, J. M. (1974). A simple apparatus for recording microsaccades during fixation. Quarterly Journal of Experimental Psychology, 26, 167-170.

Hughes, H. C., Zimba, L. D. (1985). Spatial maps of directed visual attention. Joumal of Experimental Psychology: Human Perception \& Performance, 11, 409-430.

HumphreYs, G. W. (1981). On varying the span of visual attention. Quarterly Journal of Experimental Psychology, 33A, 17-31.

JONIDES, J. (1981). Voluntary versus automatic control over the mind's eye. In J. Long \& A. Baddeley (Eds.), Attention and performance (Vol. 9, pp. 187-203). Hillsdale, NJ: Erlbaum.

KIRK, R. E. (1968). Experimental design: Procedures for the behavioral sciences. Belmont, CA: Brooks/Cole.

KLEIN, R. (1980). Does oculomotor readiness mediate cognitive control of visual attention? In R. S. Nickerson (Ed.), Attention and performance (Vol. 8, pp. 259-276). Hillsdale, NJ: Erlbaum.

Kowler, E., Steinman, R. M. (1979a). The effect of expectations on slow oculomotor control: 1. Periodic target steps. Vision Research, 19, 612-632.

Kowler, E., \& Steinman, R. M. (1979b). The effect of expectations on slow oculomotor control: 2 . Single target displacements. Vision Research, 19, 633-646.

LABERGE, D. (1983). Spatial extent of attention to letters and words. Journal of Experimental Psychology: Human Perception \& Performance, 9, 371-379.

MAYLOR, E. A. (1985). Facilitatory and inhibitory components of orienting in visual space. In M. I. Posner \& O. S. M. Marin (Eds.), Attention and performance (Vol. 11, pp. 189-204). Hillsdale, NJ: Erlbaum.

Mclean, J. P., \&hulman, G. L. (1978). On the construction and maintenance of expectancies. Quarterly Journal of Experimental Psychology, 30, 441-454.

Müller, H. J., FindLAY, J. M. (1987). Sensitivity and criterion effects in the spatial cuing of visual attention. Perception \& Psychophysics, 42, 383-399.

Müller, H. J., RABbitt, P. M. A. (in press). Reflexive and voluntary orienting of visual attention: Time course of activation and resistance to interruption. Journal of Experimental Psychology: Human Perception \& Performance.

MuRPhy, T. D., \& ERIKSEN, C. W. (1987). Temporal changes in the distribution of attention in the visual field in response to precues. Perception \& Psychophysics, 42, 576-586.

PosNer, M. I. (1980). Orienting of attention. Quarterly Journal of Experimental Psychology, 32, 3-25.

POSNER, M. I., \& COHEN, Y. (1984). Components of visual orienting. In H. Bouma \& D. G. Bouwhuis (Eds.), Attention and performance (Vol. 10, pp. 531-555). Hillsdale, NJ.: Erlbaum.

Posner, M. I., Crippin, P. J., Cohen, A., \& Rafal, R. (1986, November). Speed of covert orienting of attention and express saccades $I$. Paper presented at the annual meeting of the Psychonomic Society, New Orleans. 
Posner, M. I., Rafal, R. D., Choate, L. S., \& Vaughan, J. (1985). Inhibition of return: Neural basis and function. Cognitive Neuropsychology, 2, 211-228.

Posner, M. I., Snyder, C. R. R., \& Davidson, B. J. (1980). Attention and the detection of signals. Journal of Experimental Psychology: General, 109, 160-174.

Remington, R., \& PierCe, L. (1984). Moving attention: Evidence for time-invariant shifts of visual selective attention. Perception \& Psychophysics, 35, 393-399.

Rizzolati, G., Riggio, L., Dascola, I., \& Umiltà, C. (1987). Reorienting attention across the horizontal and vertical meridians: Evidence in favour of a premotor theory of attention. Neuropsychologia, $25,31-40$.

Rosenbaum, D. A., Inhoff, A. W., \& Gordon, A. M. (1984). Choosing between movement sequences: A hierarchical editor model. Joumal of Experimental Psychology: General, 113, 372-393.

SHEPHERD, M. (1984). EMDISP: A visual display system with digital and analogue sampling. Behavior Research Methods, Instruments, \& Computers, 16, 297-302.

ShePHERD, M., Findlay, J. M., \& HoCKEY, R. J. (1986). The relationship between eye movements and spatial attention. Quarterly Journal of Experimental Psychology, 38, 475-491.

Shulman, G. L., Remington, R. W., \& McLean, J. P. (1979). Moving attention through visual space. Journal of Experimental Psychology: Human Perception \& Performance, 5, 522-526.

TSAL, Y. (1983). Movements of attention across the visual field. Journal of Experimental Psychology: Human Perception \& Performance, 9, 523-530.

\section{NOTES}

1. Other questionable assumptions and internal inconsistencies in the data of proponents of the movement model have been pointed out in a very thorough critique by Eriksen and Murphy (1987).

2. Direct monitoring of subjects' fixation by the experimenters seemed adequate, given the large stimulus eccentricities $\left(10^{\circ}\right.$ or $\left.20^{\circ}\right)$ and the mostly brief SOAs. The ability of the experimenters to detect saccades to near and far cued locations was assessed in a preliminary study and was found to be nearly perfect. Nevertheless, because of fluctuations in concentration, detection was presumably less than perfect in the experiments themselves. The 500-msec SOA data, which might be affected by undetected eye movements, should therefore be interpreted with caution.

3. There was one exception: when the far location was cued, the samenear location showed some evidence of facilitation at the 150- and 200msec SOAs. However, when we repeated this condition with 5 new sub-
Table 4

Mean Reaction-Time Benefits and Costs (in msec) for Cued (Same-Far) and Uncued (Same-Near, Opposite-Near, Opposite-Far) Locations as a Function of SOA (in msec)

\begin{tabular}{lcccc}
\hline \multirow{2}{*}{$\begin{array}{c}\text { Target } \\
\text { Location }\end{array}$} & 50 & 150 & 200 & 500 \\
\cline { 2 - 5 } & $+41 \ddagger$ & $+15 \dagger$ & +8 & $+15 \dagger$ \\
Same-Far & -5 & -8 & -5 & $-15^{*}$ \\
Same-Near & -6 & -12 & -11 & $-32 \ddagger$ \\
Opposite-Near & $-17^{*}$ & $-32 \ddagger$ & $-33 \ddagger$ & $-48 \ddagger$ \\
Opposite-Far &
\end{tabular}

Note-Simple main effects: ${ }^{*} p<.05, \dagger p<.025, \ddagger p<.005$.

jects, no facilitation for any of the uncued locations was obtained (see Table 4 for the mean benefits and costs for same-far, same-near, opposite-near, and opposite-far locations). We therefore do not consider the above exception any further.

4. We cannot rule out the possibility that undetected eye movements reduced the benefits for cued locations at long SOAs. That is, there is evidence (C. W. Eriksen, personal communication, November 1988) that if subjects engage in eye movements at longer SOAs, this might impair performance rather than facilitate it.

The finding that facilitation tended to decrease to nonsignificant levels at longer SOAs with peripheral cues is reminiscent of data obtained when peripheral cues were uninformative (e.g., Maylor, 1985); in that case, strong facilitation at short SOAs (100 msec) was followed by no difference between cued and uncued locations at intermediate SOAs (300 msec) and by inhibition at longer SOAs $(500 \mathrm{msec})$. According to Posner and Cohen (1984), this "inhibition" effect occurs because "some part of the pathway from the cued location is reduced in efficiency by the '[peripheral]' cuing" (p. 537), thus favoring the sampling of areas of the visual field at which there was no previous change in light energy. Posner, Rafal, Choate, and Vaughan (1985) found that this effect is dependent on (the absence of lesions to) midbrain centers involved in the control of saccadic eye movements.

5. Müller \& Findlay (1987) found that in a central cuing experiment in which saccadic eye movements had to be suppressed, oculomotor preparation was nevertheless manifest in slow fixation drifts (with velocities of less than $0.5^{\circ} / \mathrm{sec}$ ), predominantly in the expected direction (see also Kowler \& Steinman, 1979a, 1979b).

(Manuscript received August 10, 1987; revision accepted for publication January 18, 1989.) 